Article

www.mdpi.com/journal/molecules

\title{
Lead Generation and Optimization Based on Protein-Ligand Complementarity
}

\section{Koji Ogata $^{1, \dagger}$, Tetsu Isomura ${ }^{2, \dagger}$, Shinji Kawata ${ }^{3}$, Hiroshi Yamashita ${ }^{3}$, Hideo Kubodera ${ }^{3}$ and Shoshana J. Wodak ${ }^{1,4,5, *}$}

1 Centre for Computational Biology, The Hospital for Sick Children, 555 University Avenue, Toronto, Ontario M5G 1X8, Canada

2 Advanced Medical Research Laboratories, Mitsubishi Tanabe Pharma Corporation, 1000, Kamoshida-cho, Aoba-ku, Yokohama, Kanagawa 227-0033, Japan

3 Medicinal Chemistry Research Laboratories, Mitsubishi Tanabe Pharma Corporation, 1000, Kamoshida-cho, Aoba-ku, Yokohama, Kanagawa 227-0033, Japan

${ }^{4}$ Depart ment of Biochemistry, University of Toronto, Toronto, Canada

5 Department of Molecular Genetics, University of Toronto, Toronto, Canada

$\dagger$ These authors contributed equally to this work.

* Author to whom correspondence should be addressed; E-Mail: shoshana@sickkids.ca; Tel.: +1 416813 6351; Fax: +1 4168138339 .

Received: 24 May 2010 / Accepted: 7 June 2010 / Published: 17 June 2010

\begin{abstract}
This $\mathrm{w}$ ork propose s a c omputational procedure fo $\mathrm{r}$ st ructure-based lead generation and opti mization, $w$ hich reli es on the complementarity of $t$ he prote in-ligand interactions. This procedure takes as input the known structure of a protein-ligand complex. Retaining the positions of the lig and heavy at oms in the p rotein bind ing site it d esigns structurally similar compounds considering all possible combinations of atomic species $(\mathrm{N}$, $\mathrm{C}, \mathrm{O}, \mathrm{CH}_{3}, \mathrm{NH}$, etc). Compounds are ranked based on a score which incorporates energetic contributions evaluated using molecular mechanics force fields. This procedure $\mathrm{w}$ as used to design $n$ ew inhib itor m olecules for three serine/threon ine protein kinases (p38 MAP kinase, p42 MAP kinase (ERK2), and c-Jun N-terminal kinase 3 (JNK3)). Fo r each enzyme, the calcu lations produce a se t of poten tial in hibitors wh ose sc ores are in
\end{abstract}


agreement with IC50 data and Ki values. Furthermore, the native ligands for each protein target, scored within the five top-ranking compounds predicted by our method, one of the top-ranking co mpounds pr edicted to inh ibit JNK3 was s ynthesized and h is in hibitory activity confir med against ATP hydrolysis. Our co mputational pr ocedure is th erefore deemed to be a useful tool fo $r$ generat ing chemically divers e molecules active ag ainst known target proteins.

Keywords: loc k-and-key proble m; co mputational structure-based d rug design; lead generation; lead optimization

\section{Introduction}

When a high-resolution structure of a ta rget protein is known, computational structure-based drug design is an efficient and effective methodology for the identification and fur ther optimization of hit compounds in order to generate lead co mpounds. Several studies [1-3] have reported the successful identification of hi $\mathrm{t}$ molecules by in sil ico scr eening of large compound datab ases using software packages such as DOCK [4], G OLD [5,6] and eHiTS [7]. In many cases, how ever, iden tified hit s exhibit w eak biological a ctivity and poor Adsorption, Distribution, Meta bolism, Ex cretion and Toxicity (ADMET) properties, $m$ aking them uns uitable scaffolds for further optim ization. Consequently, new strategies have to be developed in order to derive molecules with better biological properties from such hits.

Standard hit co mpound optimization approaches involve the addit ion, replacement or rem oval of chemical groups within the hit molecule. However, enhancing the biological activity of the hit often requires a more drastic modification of the core molecular skeleton [8]. De novo design [9-13] and scaffold hop ping techniques [14-26] are ex amples of methods that invo lve su ch modifications. The general assumption underlying these methods is that compounds with similar geometries will interact in a similar manner with the target protein and therefore, w ill show similar or improved inhibitory activity. This assumption is based on the lock-and-key model for p rotein-ligand interactions [27] and most of the methods are based in making changes in the $\mathrm{n}$ ative moiety of the ligand scaffolds and their geometries.

In this $\mathrm{p}$ aper, we report th e application of a co mputational method for structure-based ligand optimization to $t$ hree serine/threonine protein kinase systems: p38 MA P kinase, p42 MAP Kinase (Erk2), and c-Jun N-terminal kin ase 3 (JNK3). Our method uses as st arting p oint, th e atomic coordinates of the p rotein-ligand complex, determined by X-ray Cry stallography, NMR, or modeling techniques [28]. A large number of compound candidates are generated by replacing the atoms of the native ligand with different substituents, keeping fixed the ato mic positions of its core skeleton. Each new co mpound replaces $\mathrm{t}$ he $\mathrm{n}$ ative $\mathrm{l}$ igand in the protein active site co mplementarity and the ne $\mathrm{w}$ protein-ligand co mplex is scored in or der to rank lead candidates. The top rank ing co mpounds are selected for furthe $r$ analysis. The innovation of our approach lies in the way in which the library of 
compound candidates is generated as w ell as in the rapid identification of the ch emical groups (and combinations thereof) that is likely to enh ance biolog ical activity. Our method identifies the native ligands a mong the top $\mathrm{f}$ ive $\mathrm{h}$ it compounds for $\mathrm{t}$ he three serine/threon ine Kinases analyzed here. In addition, the fi ve top $\mathrm{r}$ anking co mpounds e xhibit significant IC50 lev els against ATPase activity $[29,30]$. In the JNK $3 \mathrm{~s}$ ystems, a co mpound fro $\mathrm{m}$ the 10 top ranking cand idates $\mathrm{w}$ as chem ically synthesized and IC50 measurements showed inhibitory activity against ATP hydrolysis. These results suggest that our method can be useful in the identification and generation of lead compounds as drug candidates.

\section{Results and Discussion}

Our a pproach was tested using $\mathrm{t}$ hree serine/threonine pro tein kinases as $\mathrm{t}$ argets. The $\mathrm{X}$-ray protein-ligand c omplexstru ctures used in his study were: $\mathrm{p} 38$ MAP kinase/3-(4-fluorophenyl)-2-pyridin- 4-y 1-1H-pyrrolo[3,2-b]pyridine-1-ol (FPH) co mplex, p42 MAP Kinase (Erk2)/N-benzyl-4-[4-(3-chlorophenyl)-1H-pyrazol-3-yl]-1H-pyrole-2-carboxamide (33A) complex, and c -Jun N-terminal ki nase 3 (JNK3)/N-(3,4-dichlorophenyl)-4-hydroxy-1-methyl-2,2-dioxo1,2-dihydro-2lamda 6 -thieno[3,2-c][1,2]thiazine-3-carboxamide (in h ouse cod e Z1208) c omplex obtained from the Protein Data Bank (PDB) [31] (see Table 1). In preparing the input structures for our calculations, the FPH and Z1208 were modified as mentioned in Experimental section (Figure 1).

Table 1. Proteins and ligands used in this study.

\begin{tabular}{|c|c|c|c|c|}
\hline Protein names & $\begin{array}{l}\text { PDB } \\
\text { entry }\end{array}$ & Name of ligands & PDB entry & MW \\
\hline Map kinase P38 & $1 \mathrm{oz} 1$ & $\begin{array}{l}\text { 3-(4-FLUOROPHENYL)-2-PYRIDIN-4-YL-1H-PYRROLO- } \\
\text { [3,2- B]PYRIDIN-1-OL }\end{array}$ & $\mathrm{FPH}^{1}$ & $\begin{array}{c}305.3 \\
06\end{array}$ \\
\hline $\begin{array}{l}\text { Map kinase } \\
\text { ERK2 }\end{array}$ & 2oji & $\begin{array}{l}N \text {-BENZYL-4-[4-(3-CHLOROPHENYL)-1H-PYRAZOL-3-YL]- } \\
\text { 1H-PYRROLE-2-CARBOXAMIDE }\end{array}$ & $33 \mathrm{~A}$ & $\begin{array}{c}376.8 \\
39\end{array}$ \\
\hline $\begin{array}{l}\text { c-Jun N-terminal } \\
\text { kinase } 3 \text { (JNK3) }\end{array}$ & 2ok1 & $\begin{array}{l}N \text {-BENZYL-4-[4-(3-CHLOROPHENYL)-1H-PYRAZOL-3- } \\
\text { YL]-1H-PYRROLE-2-CARBOXAMIDE }\end{array}$ & $33 \mathrm{~A}$ & $\begin{array}{c}376.8 \\
39\end{array}$ \\
\hline $\begin{array}{l}\text { c-Jun N-terminal } \\
\text { kinase } 3(\mathrm{JNK} 3)\end{array}$ & NA & $\begin{array}{l}\text { N-(3,4-DICHLOROPHENYL)-4-HYDROXY-1-METHYL-2,2- } \\
\text { DIOXO-1,2-DIHYDRO-2LAMBDA 6 -THIENO[3,2-c][1,2] } \\
\text { THIAZINE-3-CARBOXAMIDE }\end{array}$ & $Z 1208^{2}$ & $\begin{array}{c}405.2 \\
78\end{array}$ \\
\hline
\end{tabular}

1 The prediction was used for a modified compound $\mathrm{i}$ which $\mathrm{t}$ he $\mathrm{OH}$ group $\mathrm{i} n$ pyrrolo[3,2-b]pyridine ring was replaced by a hydrogen; ${ }^{2}$ The tertiary structure was determined by $\mathrm{X}$-ray crystallography at ZOEGENE Corp. 
Figure 1. Chemical structures of the native compounds and modifications made to create the input files for our calc ulations (see text for details). $T$ he portion surrou nded by the dotted circle was replaced as indicated in the text, and pos ition numbers are displayed for illustrative purposes.

(a)

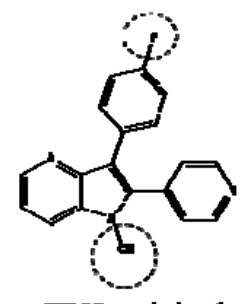

FPH_original

(b)

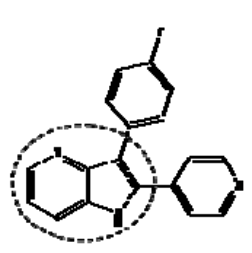

(c)

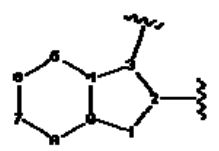

FPH

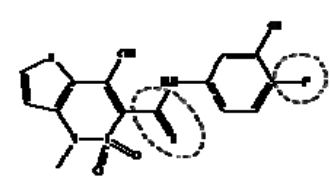

Z1208_original
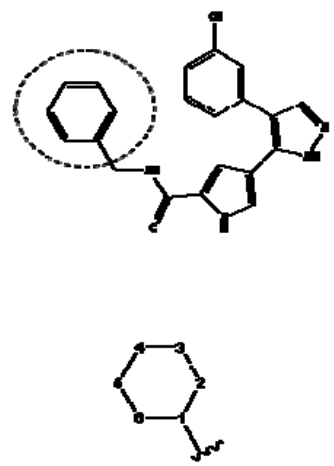

33A
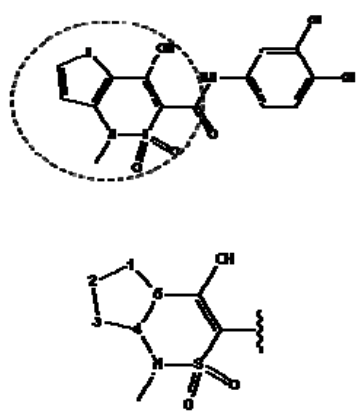

Z1208

\subsection{Redesign of the FPH ligand}

For the FPH-p38 MAP kinase complex, 230 candidate molecules were obtained by our calculations after the various filters have been app lied. Our results show that the preferred atoms for position 5 in the 6-membered ring (see Figure 1c) were either $-\mathrm{O}-$ or $-\mathrm{N}=$, to enable hydrogen bond formation with the $\mathrm{N} \zeta$ of Ly s53 (numbering as in the PDB entry 1oz1) (see Figure 2a). The sam e hydrogen bond is observed in the original structures of the p38-FPH complex [30]. In order $t$ o maintain this hydrogen bond, bu t also satisfy the bond orders of $t$ he 5- and 6-condens ed membered rings, speci fic combinations of the ato mic species containing single and double bonds are required. For exa mple, if an -O- group is assigned at position 5 (see Table 2), other positions in the molecule could be occupied by either sp2 atoms (ex. compound 1, 5 and 8), or the combination of two sp3 atoms and six sp2 atoms (ex. compound 3,4 ). If a $\mathrm{n}-\mathrm{N}=$ group is assigned at position 5 , the o ther positions in the molecule could be occupied by one sp3 atom and seven sp2 ato ms (for example, compounds 2,6 ). Detailed analysis of the p38-FPH binding site, revealed that the co ndensed FPH ring formed hy drophobic interactions with Val38, Leu171, and the aromatic ring of Tyr35 (see Figure 2). These interactions are maintained by some of the compounds described earl ier in this paragraph. In su mmary, our method assigned a hydrogen bond acceptor groups to position 5 and hydrophobic groups to the other positions in the condensed rings thereby satisfying binding features observed in the original crystal structures. 
Table 2. The 10 highest scoring FPH substitutions for the FPH-p38 MAN kinase complex.

Ranking Compounds $\begin{gathered}\text { Score } \\ \text { (Kcal/mol) }\end{gathered}$ Ranking

Figure 2. FPH-p38 MAN kinase co mplex analysis. Binding c onformations of (a) native $\mathrm{FPH}$, and (b) the top scoring compound in our calculations.
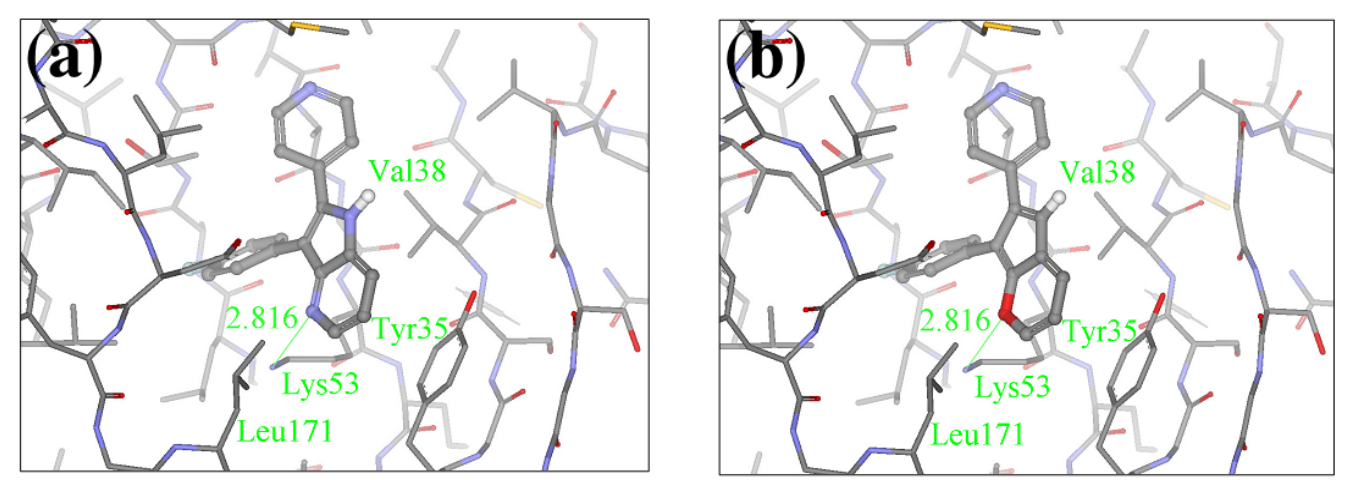

We find that the scores computed by our method for the four compounds 9, 22, 24, and 35, correlate well with the experimental IC50 values (see Table 3). In addition, the suggested top-scoring compound (compound 9), also features the lowest IC50 among the six compounds. In this candidate, the geometry of native FPH (see Figure 1) was modified by replacing a hydroxyl group with a h ydrogen atom, as mentioned below (Section 3.2). Having introduced this modification, we might expect that the binding mode of the modified co mpound would differ somewhat from the native lig and. However, in the current version of ou $r$ method such alternat ive bi nding modes are not con sidered. Wi thout 
experimental information on the bin ding mode of compound 9 , it is therefore di fficult to accu rately evaluate at this point the actual predictive power of our calculations.

Table 3. Calculated scores versus $\mathrm{IC}_{50}$ values for $\mathrm{FPH}$ substituents.

Compounds

We also find that the scores of low ranking compounds tend to be inconsistent with their $\mathrm{IC}_{50}$ values. For example, compounds 15 and $19 \mathrm{a}$, whose ranks are 153 and 156 respectively, have $\mathrm{IC}_{50}$ values of 3,100 $\mathrm{nM}$ and 1,800 $\mathrm{nM}$ (see Table 3). Ho wever, despite the discrepan cy in these valu es, our calculations indicate the correct binding trend since the scores of both compounds, are positive, which is indicativ e of unfavo rable bi nding energ ies, in agr eement wi th th eir experimental IC ${ }_{50}$ valu es. Detailed analysis of the generated structures suggests that this unfavorable score can be explained by the lack of hydrogen bond capability of position 5 in these compounds, as stated above (see Figure 2).

\subsection{Redesign of the 33 A scaffold to optimize ERK2 binding}

The ATP binding sites in ERK2 and JNK3 exhibit different chemical compositions and in particular different ratios of hydrophilic versus hydrophobic residues (see Figures 3a,b). Consequ ently, ligand 33A displays differe nt binding or ientations in ERK2 and J NK3, with the chlorobenzene moieties oriented in opposite directions. An alysis of the ERK2 complex stru cture re vealed contacts between positions 3 a nd 5 of the a romatic ring of the ligand with hy drophobic groups of the protein $(\mathrm{C} \alpha$ in Gly32, C $\gamma 2$ in Val37 and C $\delta$ in Lys52) (see Figure 3a). Hydrophobic groups were hence the preferred 
substituents for thes e two ring $\mathrm{p}$ ositions. Fu rthermore, position $4 \mathrm{oft}$ he aromatic $\mathrm{r}$ ing sho wed interactions with the carbonyl oxygen of Ala33, suggesting hydrogen bond donor groups as preferred subtituents for this position.

Figure 3. Structures of the complexes of 33A with (a) ERK2 and (b) JNK3, respect ively. Both the proteins and the ligand are displayed using stick models, with the ligand shown using thicker bonds. Co mparison of pan els (a) and (b) illus trate th e difference in orientation of $33 \mathrm{~A}$ in the two structurally aligned proteins.
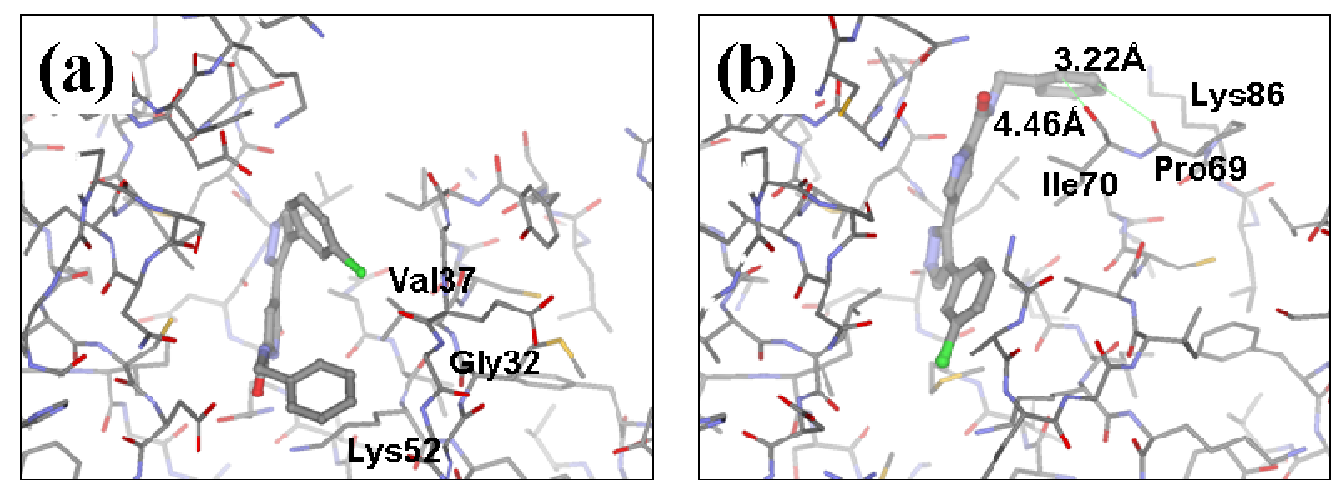

Our cal culations y ielded 23 di fferent sub stituents for th e A3 3 ri ng scaffold (Fi gure 1c), wit $\mathrm{h}$ benzene moiety having the top score for the ligands-ERK2 complexes (see Table 4).

Table 4. Five best scoring substitutions for the complexes ERK2 and JNK3 kinases with A33.

Ranking Substitutions $\quad$ Score $\quad \mathbf{K i}^{2} \mathbf{u M}^{\mathbf{1}}$ Ranking

${ }^{1}$ Ki values are from the article by Aronov et al. [29]; ${ }^{2}$ ND (Not determined). Authors reported that compound 4 was 3 -fold less active than 1 and compound 5 was 2 -fold less active. 
These results are in agreement with the inhibitory activity (lowest $K_{i}$ value) previously reported [29] and can $b$ e explained $b y$ the hydrophobic in teractions between the aromatic ring and th e active site protein residues. The substitution of $\mathrm{a}-\mathrm{CH}$ residue by $-\mathrm{N}=$ decreases the hydrophobic interactions and may explain the lower score values of the other designed compounds. The exception to this rule is the $5^{\text {th }}$ ranking compound where the addition of $-\mathrm{N}=$ residue to position 4 in the aromatic ring increased the repulsive energy (d ecreasing th e ov erall score) due to the proxi mity of $t$ his substituent $t o$ the carbonyl oxygen of the residue Ala33. This effect is enhanced by the fact that our software is using a fixed g eometry approx imation. Two approache $\mathrm{s}$ ar e currently bein $\mathrm{g}$ devel oped to $\mathrm{i}$ mprove th is methodology: (a) consideration of different co mpound conform ations, and (b) relaxati on of the protein-ligand complex in order to relieve any residual strain.

\subsection{Redesign of the $33 \mathrm{~A}$ scaffold to optimize JNK3 binding}

Analysis of the $3 \mathrm{D}$-structure of the 33A-JNK3 co mplex reve aled that the ring scaffold to $\mathrm{b}$ e modified interacts with Lys68, Pro69 and Ile70 (see Figure 3b). The ring positions 2 and 3 are close to the carbonyl oxygen atoms of the protein residue Pro69 and Ile70, while the rest of the ring atoms are surrounded by hy drophobic residu es. Therefore, positi ons 2 and 3 were assigned positively charged substituents, whereas hydrophobic substituents were assigned for the remaining ring positions.

Subject to these constraints, our procedure sampled a to tal of 23 substitutions for the 6-membered $33 \mathrm{~A}$ ring (Figure 1c). Here too, our results revealed benzene moiety to be the best ranking compound in agree ment with the experimental data[29], with a similar ration ale as for the ERK2. Our second "best c ompound" con tains an -O- at ri ng pos ition 2 a nd an - $\mathrm{NH}$ - group at ring position 3 . The somewhat lower score of this co mpound is due to close polar con tact with backb one ato ms of the protein. This score is driven by the stabilizing energy from the proximity between ligand - NH - to the carbonyl oxygen $\mathrm{O}$ of Pro69 (3.23 $\AA$ ), and the repulsive energy for the interaction between the ligand $-\mathrm{O}-$ at position 2 with the carbonyl oxygen of Ile70 (4.46 $\AA$ ).

The co mpounds with 2-, 3- and 4-p yridine moieties w ere ranked at $3 \mathrm{rd}$, 4th and 5th positions, respectively. With respect to the calculated "best compound", these scor es can be ration alized in the same way as i n the case of E RK2 case, by a d ecrease in hydrophobic in teractions. How ever, the authors of the experimental paper [29] found th at compounds with 3- and 4-pyridine moieties do not bind to JNK3, which underscores the difficulty in discrim inating between co mpounds that bind from those that do not bind, based on our computed scores alone.

\subsection{Redesign of the Z1208 scaffold bound to JNK3.}

The cry stal structure of the native Z1208 with JNK3 complex sugg ests that the lig and is tigh tly bound to the ATP binding pocket of the protein (Figure 4). 
Figure 4. Binding site of the native Z1208 JNK3 complex.

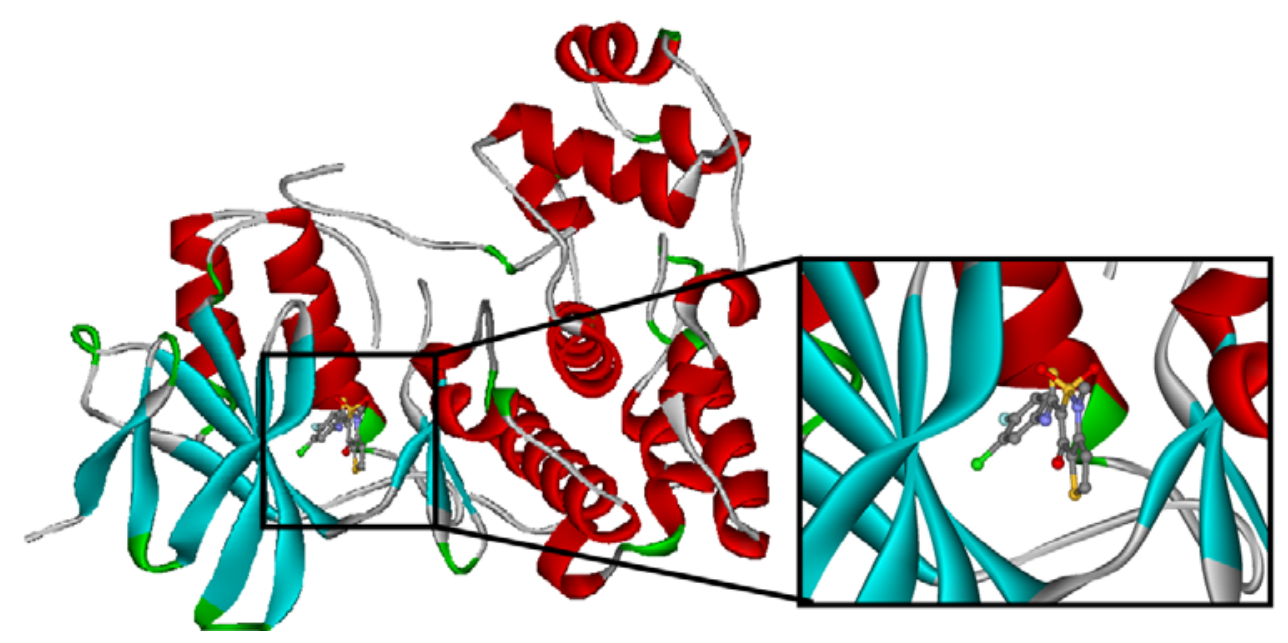

One water molecule appears in the binding site forming hydrogen bonds with the protein backbone (carbonyl oxygen of the G lu147 and the amide nitrog en of Met149) and the h ydroxyl group of the condensed ring in the native Z1208 (Figure 5a). Analysis of JNK3-ligand complexes in the PDB show that hydrogen bond interactions between the ligand and the backbone atoms of Glu147 and/or Met149 are common, but the water molecule is not present in all the structures. Therefore for the purpos e of this study the water molecule $\mathrm{w}$ as rem oved. Further more, in the binding site , th $\mathrm{e}$ 3-chloro-4-fluoro-phenyl moiety of the native Z1208 ligand is pos itioned near Met1 46 of JN K3 and surrounded by other h ydrophobic residues (Figure 4). According to $\mathrm{S}$ capin et al. [32], JNK 3 complexes with i midazole-pyrimidines (PD B-codes: 1q $\mathrm{mn}$ and 1qmq) that have h alogen-phenyl moieties, fea ture $d$ ifferent confor mations of $t$ he $M$ et146 si de chain th an in the complex with AMP-PNP (PDB-code 1jnk). We found that the stru cture of J NK3 protein in the complex with Z1208_original, superimposed well onto those of the JNK3 proteins in 1qmn and 1 qmq. In addi tion the Met146 adopts a similar conformation on all three complexes.

Figure 5. Conformations of (a) native Z1208 and (b) Z1208_8 binding to JNK3.
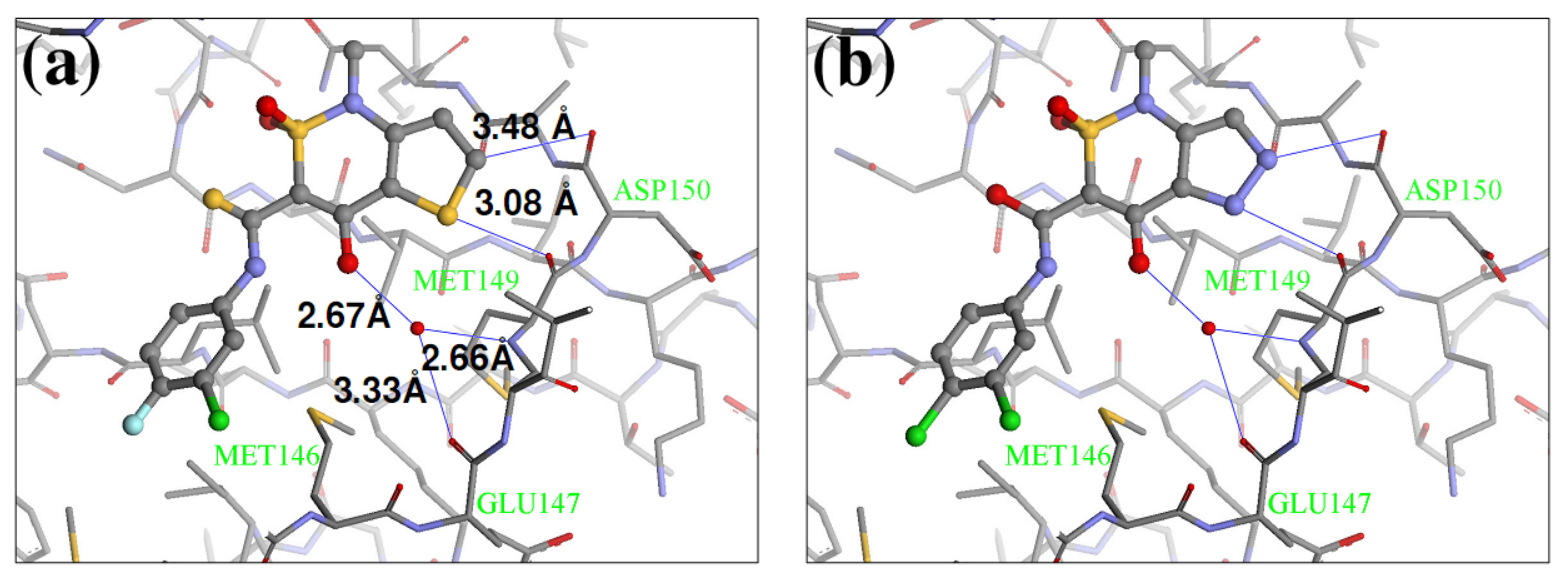
Our calculations gen erated 64 designed compounds. The to $\mathrm{p} 10$ rankin $\mathrm{g}$ compounds are displayed in Table 5. Co mpounds with the best and the second best scores contain one-NH-group in different positions of the 5-membered ring. The add ition of a seco nd substit uent in the sam e ring of the molecule $(-\mathrm{NH}-$ and $-\mathrm{N}=)$, produced only a slightly higher sc ore (compound 8 in Table 5). Visual inspection of the modeled ligand-protein active site reveals that oxygen atoms in Met149 and Asp150 make contacts in the 5-membered ring, and those atoms are engaged in repulsive interactions when the negatively charged $-\mathrm{N}=$ groups are introduced (Figure 5a). Hence replacements which combine sulfur or carbon atoms with the $-\mathrm{NH}-$ group is preferable to those of two $-\mathrm{N}=$ groups.

Table 5. Ten best scoring substitutions of Z1208 bund to JNK3 and their IC50 values.

Ranking Substitutions Score IC50 (uM) Ranking (uM)

We see that the native compound is ranked 4th in this list, but its score is only slightly worse than the pred icted best-scoring ligand. Unfortunately, the chemical s ynthesis of all three best ranking compounds was very $d$ ifficult with current techniques, $d$ emonstrating that th $\mathrm{e} f$ ilters used in the pre-calculation steps w ere not suffic ient to remove all the unsy nthesizable compounds and $h$ ence further improvements of the various filters used in our procedure are required. Nevertheless, it is quite encouraging that the native ligand was the top ranking synthesizable compound. 


\subsection{Discussion}

Additional validation of our method by synthesis of one molecule

An additional validation method step was $\mathrm{c}$ arried out by synthesizing in the laboratory one of the top-ranking newly designed inhibitors. The chosen compound was Z1208-8, ranked 8th in Table 5, and its inhibitory activity was measured against A TP hydrolysis by JNK3. This compounds was selected because it was easier to synthesize compared to other higher ranked compounds in the same list.

The biological assay showed that Z 1208-8 was a ble to inhibit ATP binding to JNK3 with an I $\mathrm{C}_{50}$ $62.9 \mu \mathrm{M}$, representing a six fold poorer activity than the native ligand (Z1208, 9.6 $\mu \mathrm{M})$. The analysis of the 3D structure of the X1208-8/JNK3 complex indicated that the two major contributions to the overall energy score are: 1) the NH group in the 5-membered ring forming a hydrogen bond with the carbonyl oxygen of Asp150, which would favor binding, and 2) a close contact of the $-\mathrm{N}=$ group in the 5-membered ring with the backbone oxygen of Met149 (Figure 5b), which would disfavor bin ding. The second contribution is higher in Z1208-8 higher th an in the native co mpounds, suggesting an explanation to the higher $\mathrm{IC}_{50}$ value observed in the new inhibitor.

Our method is thus capable of d esigning new compounds with inhibitor activity against the target enzyme, but their activity can be lower than that of the starting hit compound. We expect however, that several cy cles of rati onal design using our method and experim ental an alysis of the top rankin $g$ candidates should lead not only to compounds with different che mical properties from those of the original molecule, but also to those with a strong or stronger inhibitory activity.

This paper has shown that our computational method is effective in a scaffol d-based redesign of kinase inhibitors FPH, 33A and Z1208. For a defined scaffold and keeping fixed the "geometry" of its core skeleton, our method was capable of sampling a large number of different substituents providing a set of compounds with potential inhibitory activity against the protein targets. Compounds were ranked based on an energy function, and in all the cases native inhibitors were identified in the 5 top ranking compounds. Validation of our method was performed by comparing the scores of designed molecules with e mpirical $d$ ata on their inhib itory activ ity (IC 50 and Ki valu es). In the JNK3 inhibit or desig n study, one of the top ra nked co mpounds was s ynthesized and it $\mathrm{s}$ inhibitory ac tivity was confirmed experimentally.

Future dev elopments $\mathrm{w}$ ill address the following out standing limitations of o ur method: 1) more effective filters to rem ove co mpounds difficu lt or impossible to sy nthesize, 2) i mprove the scoring function to enh ance co mpound $r$ anking accuracy, and 3) tak e into account protein and ligand conformational flexibility and different ligand poses in the protein active site. With the introduction of these improvements, our computational approach holds the promise of becoming a useful tool for lead optimization. 


\section{Experimental}

\subsection{Lead optimization procedure}

The lead/hit optimization procedure used in this study was previously reported by Ogata et al [33] and is only briefly summarized here. The first step consists in extracting the atomic coordinates of the ligand's heavy atoms (referred to as 'geometry') from a high resolution structure of the protein-ligand complex. The geometry is then divided into fragments which are grouped into three partial structures types: rings, linkers (defined as the fragments that connect rings), and terminals (defined as other types of frag ments). In addit ion, all the atoms in the geometry are classified according to their bond order types (sp3, sp2, etc ) an d atomic species $\left(\mathrm{CH}_{3}, \mathrm{CH}_{2}, \mathrm{CH}, \mathrm{NH}_{2}, \mathrm{NH}\right.$ etc). For example, consider the geometry $\mathrm{X} \cdot \mathrm{Y} \cdot \mathrm{Z}$, in which $\mathrm{X}, \mathrm{Y}$, and $\mathrm{Z}$ represent the atoms in the geometry and '...' is a generic representation of the bonds conn ecting the atoms. Repl acing $\mathrm{Y}$ with a " $=\mathrm{CH}-$ " generates a chemically incomplete compound $\mathrm{X}=\mathrm{CH}-\mathrm{Z}$ for which "=" and "-_" indicate a double and a single bond, respectively. Then, $\mathrm{X}$ should be assigned to an atomic species linked through a double bond to $\mathrm{Y}$ (ex. $\mathrm{O}=$ or $\mathrm{CH} 2=$ ). Similarly, $\mathrm{Z}$ should be assigned to an atomic species capable of linking to $\mathrm{Y}$ through a single bond (ex. $-\mathrm{CH}_{3}$ or $-\mathrm{NH}_{2}$ ). By assembling all possible combinations of these atomic species, four compounds are obtained: $\mathrm{O}=\mathrm{CH}-\mathrm{CH}_{3}, \mathrm{O}=\mathrm{CH}-\mathrm{NH}_{2}, \mathrm{CH}_{2}=\mathrm{CH}-\mathrm{CH}_{3}$, and $\mathrm{CH}_{2}=\mathrm{CH}-\mathrm{NH}_{2}$. For the work presented in this paper, eighteen atomic species were used (see Table 6).

Table 6. Atomic Chemotypes used in this study.

\begin{tabular}{|c|c|c|c|c|c|c|c|}
\hline $\begin{array}{l}\text { Atom } \\
\text { groups }\end{array}$ & Bond type & $\begin{array}{l}\text { No. of } \\
\text { bonds }\end{array}$ & $\begin{array}{c}\text { No. of } \\
\text { hydrogens }\end{array}$ & $\begin{array}{l}\text { Atom } \\
\text { groups }\end{array}$ & Bond type & $\begin{array}{l}\text { No. of } \\
\text { bonds }\end{array}$ & $\begin{array}{c}\text { No. of } \\
\text { hydrogens }\end{array}$ \\
\hline $\mathrm{s}-\mathrm{CH}_{3}$ & p3 & 4 & 3 & $-\mathrm{OH}$ & $\mathrm{sp} 3$ & 2 & 1 \\
\hline $\mathrm{s}-\mathrm{CH}_{2}-$ & p3 & 4 & 2 & $-\mathrm{O}-$ & all & 2 & 0 \\
\hline$-\underset{l}{\mathrm{C}} \mathrm{H}-$ & sp3 4 & & 1 & $=\mathrm{O}$ & all 2 & & 0 \\
\hline$-\stackrel{C}{C}-$ & sp3 4 & & 0 & & & & \\
\hline $\mathrm{s}=\mathrm{CH}_{2}$ & $\mathrm{p} 2$ & 4 & 2 & $-\mathrm{Cl}$ & $\mathrm{sp} 3$ & 1 & 0 \\
\hline $\mathrm{s}=\mathrm{CH}-$ & $\mathrm{p} 2$ & 4 & 1 & & & & \\
\hline$=c^{\prime}$ & $\mathrm{sp} 24$ & & 0 & & & & \\
\hline $\mathrm{s}-\mathrm{NH}_{2}$ & p3 & 3 & 2 & & & & \\
\hline$-\mathrm{NH}-$ & all 3 & & 1 & $-s-$ & all 2 & & 0 \\
\hline$=\mathrm{N}-$ & sp2 3 & & 0 & $=\mathrm{s}^{\prime}$ & all 4 & & 0 \\
\hline & all 3 & & 0 & & all 6 & & 0 \\
\hline
\end{tabular}


After assigning all possible combinations of atomic species to the native ligand's core coordinates, all the partial structures ar e considered and bond order requirements are satisfied thereby generating the hit compound database. Compounds in the newly generated database have similar core geometries as the native ligand and each atomic position satisfies different chemically meaningful combinations.

In a second step, compounds from the newly generated database a re subjected to two filters. The Rishton non leadlikeness filter (to remove undesira ble functional groups, see Figure 6) [34] and the Lipinski's rule of five (co mpounds $w$ ith more th an fiv e hy drogen-bond donors, more th an 10 hydrogen-bond acceptors, molecular mass greater th an $500 \mathrm{Da}, \log \mathrm{P} v$ alues greater than 5 , or more than 10 rota table b onds are not desira ble for orally acti ve drug s) [35]. F rom the re maining list of compounds, molecules with ring(s) and condensed ring structures were selecte $\mathrm{d}$ because known hits for the three targe $t$ kinase proteins contain such structures. These molecules were tr eated as the final list of lead candidates and ranked based on a scoring function, Score, evaluated for the protein-ligand complex. The scoring function comprises four empirical energy terms:

$$
\text { Score }=E_{v}+E_{e}+E_{h}+E_{s}
$$

where, $E_{v}$ is the van d eer Waals in teraction energ y, $E_{e}$ the electrost atic in teraction energy, $E_{h}$ the hydrogen bond energy, and $E_{s}$ the solvation energy.

$E_{v}$ and $E_{e}$ were obtained using the A MBER force field with the GAFF parameter set. [36] $E_{h}$ was defined as:

$$
E_{b}\left(r_{i j}\right)=\left\{\begin{array}{cc}
\exp \left(-\left(r_{i j}-r_{H}\right)^{2}\right) & 1.0 \leq r_{i j} \leq 3.0 \\
0 & \text { else }
\end{array}\right.
$$

where $r_{H}$ is the distance between the hydrogen and the heavy atom $\left(\mathrm{H}^{\cdots} \mathrm{X}\right.$, set at $2.0 \AA$ for this study).

$E_{s}$ was computed for the bound and unbound states of the ligand, protein and the complex as:

$$
E_{s}=\sum_{i} \sigma_{i} A_{i},
$$

where $A_{i}$ and $\sigma_{i}$ are $\mathrm{t}$ he solv ent-accessible s urface area and th e p roportionality fa ctor for th $\mathrm{e}$ solvent-accessible surface area of atom $i$, respectively[37]. The free energy of $G^{\text {protein }}$ and $G^{\text {compound }}$ were calculated in the same manner. This method has been designed to provide a ranked list of compounds with better "drug-type" properties (more stable, druglikeness and synthesizable co mpounds) than other approaches. 
Figure 6. Nonleadlikness filter. The subs tituent ty pes were extracted fro $m$ Rish ton work [34]. The electrophilic functional groups shown here are the most common protein-reactive covalent-acting false positives in biochemical assays. Compounds with substituents shown in this figure were removed from our results.

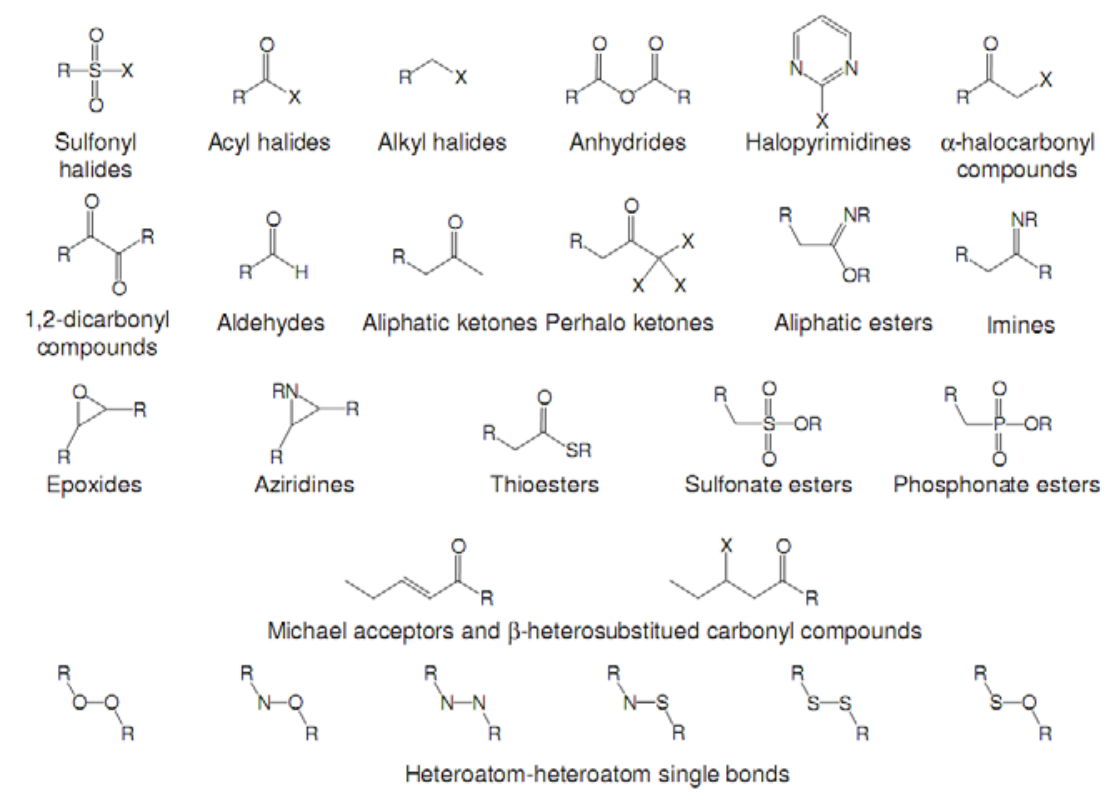

\subsection{Application to serine/threonine protein kinases}

Our a pproach was tested using t hree serine/threonine pro tein kinases as $\mathrm{t}$ argets. The X-ray protein-ligand co mplex structures used in th is st udywere: p38 MAP kinase/ 3-(4-fluorophenyl)-2-pyridin-4-yl-1H-pyrrolo[3,2-b]pyridine-1-ol ( FPH) co mplex, p 42 MAP Kinase (Erk2)/ $N$-benzyl-4-[4-(3-chlorophenyl)-1H-pyrazol-3-yl]-1H-pyrole-2-carboxamide ( 33A) co mplex, and c-Jun N-ter minal k inase 3 (JNK3)/N-(3,4-dichlorophenyl)-4-hydroxy-1-methyl-2,2-dioxo1,2-dihydro-2lamda 6 -thieno[3,2-c][1,2]thiazine-3-carboxamide (in h ouse cod e Z1208) c omplex obtained from the Protein Data Bank (PDB) [31] (see Table 2). The three structures display different ligand bind ing modes, and feature $d$ ifferences in the electrostatic potentials at th e ATP-binding site [29,30,38-40]. In addition, inhibitory activity against the target proteins has been reported for series of compounds. These compounds were derived by small modifications (changing or adding substituents) of the $n$ ative ligand structures and atom types $[29,30,38]$. We used this data to validate the results of our calculations, which involves potential co mpound ca ndidates with larger struct ural and c hemical differences than the original authors considered in their study.

In pre paring the inpu $t$ structures for our calculations, the fol lowing steps were performed (see Figure 1): 1) all water molecules were removed from the original complexes' PDB files; 2) In FPH, the hydroxyl group attached to the 5- and 6-membered condensed ring was replaced by a hy drogen atom because the modified compound has a larg er nu mber of si milar co mpounds with experimentally 
demonstrated inhibit ory a ctivity than t he native co mpound; 3) In FPH a nd Z12 08, all th e fluorin e atoms were replaced by chlorine atoms as this replacement made the chemical synthesis easier and; 4) the thioamide group in Z1208 was replaced by an amide group for the same reason.

In JNK3, two ligands were used to create the input structure: the native Z1208 and a derivative of Z1208 that acts as an ATP hydrolysis inhibitor. The experimental data used for this analysis were the in-house X-ray cry stal structure (2.1 $\AA$ resolution and R-factor $=24.6 \%$, see Figure 4$)$ and the IC50 values of $22.8 \mu \mathrm{M}$ a nd $9.6 \mu \mathrm{M}$ for nativ e Z1208 and Z1208-derived ATP h ydrolysis inhibitor respectively.

\subsection{Inhibition assay}

To measure the inhibitory activity of the Z1208, we used the following assay system: ad enosine triphosphate (A TP), ph osphoenolpyruvate (PEP), nicotinamide aden ine dinucleotide (NADH), and a solution mixture of pyruvate kinase and L-lactate dehydrogenase (PK-L-LDH) were purchas ed from Roche Di agnostics. Oth er reagen ts were purch ased fro $\mathrm{m}$ Si gma-Aldrich. JN K3 was express ed and purified by the method of Xie et al. [41]. After a purification step, JNK3 was activated by GST-fused MKK7 and further purified against a glutathione-fixed column. Inhibitory activity was estimated by detecting the inhib ition of ATP hydrolysis react ion monitored by the coupled reaction of NADH oxidation; a slightly modified method of Xie et al. Experimental conditions were: $100 \mathrm{nM} \mathrm{JNK} 3$ in $50 \mathrm{mM}$ Hepes, pH 7.6, 10 mM MgCl 2,1 mM NADH, 90 mg/mL PK, 30 mg/mL L-LDH, 2 mM PEP, 200 mM ATP, and each concentration of compound under 1\% DMSO. The conversion of NADH was measured by kinetic monitoring with SpectraMax 190 (Molecular Devices).

\subsection{Synthesis of Z1208-8}

Z1208-8 synthetic path is displayed in Scheme 1 [42-45].

Scheme 1. Steps of the chemical synthesis of Z1208-8.
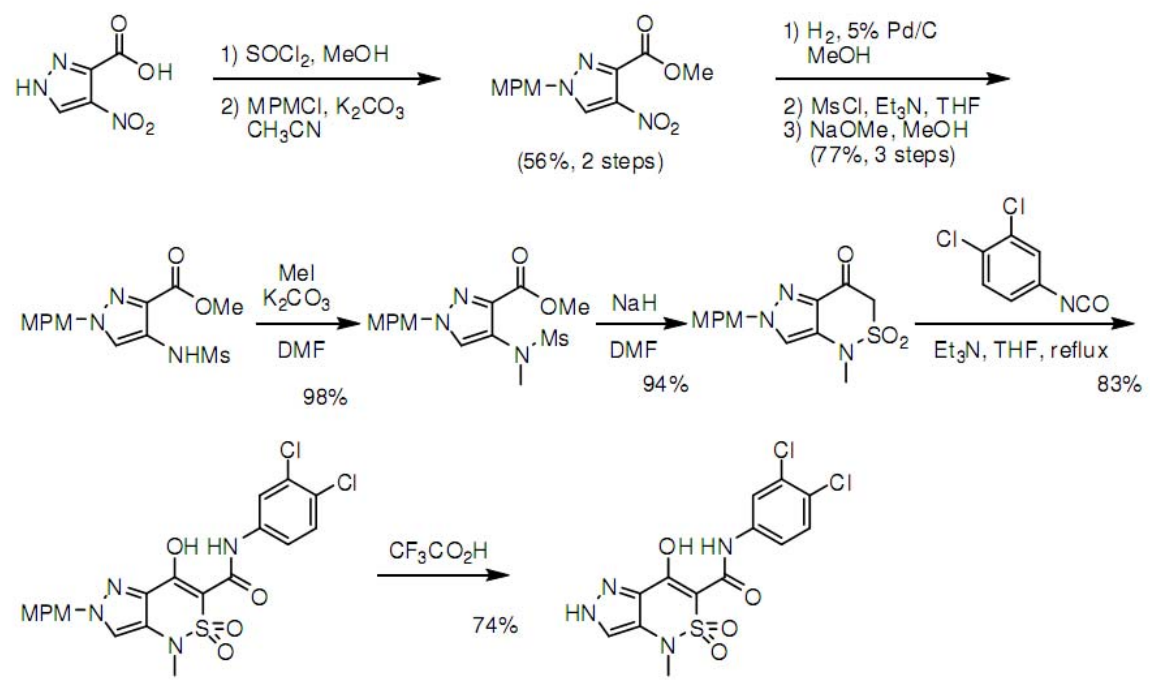


\section{Acknowledgements}

We thank H. Kitano, F. Ohno, H. Nakano and H. Kano of Mitsubishi Tanabe Pharma Corporation, S. Kondo and S. Sugio of MCRC Co rporation, and J. Gon zalez-Outeirino and V. Mallikarjunaradhya of Centre for Computational Biology in The Hospital for Sick Children for scientific discussions. We furthermore thank R. Nakanishi, C. O kumura, and S. Shi momura of Mitsubishi T anabe Pharma Corporation for technical assis tance. We a re grat eful to the st aff of the Centre for Co mputational Biology for h elp w ith the High Performance computer sy stems. SJW is Can ada R esearch Chair in Bioinformatics and Co mputational Biology, and acknowledges the Can ada Fund for Innovati on and the Canada Institute for Health Research for support.

\section{References}

1. Yamazaki, K.; Kusunose, N.; Fujita, K.; Sato, H.; Asano, S.; Dan, A.; Kanaok a, M. Identification of phosphodiesterase- 1 and 5 dual inhib itors by a ligand-based virtu al screening optimized for lead evolution. Bioorg. Med. Chem. Lett. 2006, 16, 1371-1379.

2. Yan, S.; A ppleby, T.; L arson, G .; Wu, J.Z.; Ham atake, R. K.; Hong, Z.; Yao, N . Thiazolone-acylsulfonamides as novel HCV N S5B polymerase allosteric inhibitors: convergence of structure-based drug design and X-ray crystallographic study. Bioorg. Med. Chem. Lett. 2007, 17, 1991-1995.

3. Carosati, E.; Mannhold, R.; Wahl, P .; Hansen, J.B.; Fre mming, T.; Zamora, I.; Cianchetta, G. ; Baroni, M. Virtual screening for novel openers of pa ncreatic K(A TP) channels. J. Med. Chem. 2007, 50, 2117-2126.

4. Meng, E.C.; Gschw end, D.A.; Blan ey, J.M.; Kuntz, I.D. Orientat ional sam pling and rigid-body minimization in molecular docking. Proteins 1993, 17, 266-278.

5. Jones, G.; Wi llett, P. Docking s mall-molecule ligands into active sites. Curr. Opin. Biotechnol. 1995, 6, 652-656.

6. Jones, G.; Willett, P.; Glen, R.C. ; Leach, A .R.; Tay lor, R. Develop ment and v alidation o f a genetic algorithm for flexible docking. J. Mol. Biol. 1997, 267, 727-748.

7. Zsoldos, Z.; Reid, D .; Simon, A.; Sadjad, S.B.; Johnso n, A.P. e HiTS: A new fast, exhaustive flexible ligand docking system. J. Mol. Graph. Model. 2007, 26, 198-212.

8. Zhao, H. Scaffold selection and scaffold hopping in lead gener ation: a medicinal chemistry perspective. Drug Discov. Today 2007, 12, 149-155.

9. Schnecke, V.; Bostrom, J. Computational chemistry-driven decision making in lead gen eration. Drug Discov. Today 2006, 11, 43-50.

10. Bohm, H.J. LUDI: rule-based automatic design of new subs tituents for en zyme inhibitor leads. $J$. Comput. Aided Mol. Des. 1992, 6, 593-606.

11. DeWitte, R.S.; Ishc henko, A.V.; Shakhnov ich, E.I. SMoG: de $\mathrm{N}$ ovo design method based o $\mathrm{n}$ simple, fast, and accurate free energy estimates. 2. Case studies in molecular design. J. Am. Chem. Soc. 1997, 119, 4608-4617. 
12. Gehlhaar, D.K .; Moerder, K.E.; Zichi, D.; Sh erman, C.J.; Ogd en, R.C.; Freer, S.T. De no vo design of enzyme inhibitors by Monte Carlo ligand generation. J. Med. Chem. 1995, 38, 466-472.

13. Nishibata, Y.; Itai, A. Confirmation of usefulness of a structure construction program based on three-dimensional recept or structure for rational lea d gene ration. J. Med. C hem. 1993, 36, 2921-2928.

14. Ahlstrom, M .M.; Ridd erstrom, M. ; Lu thman, K.; Zam ora, I. Virtu al scr eening and s caffold hopping based on GRID molecular interaction fields. J. Chem. Inf. Model 2005, 45, 1313-1323.

15. Bergmann, R.; L inusson, A .; Zamora, I. S HOP: Scaffold HOPping by GRID -Based S imilarity Searches. J. Med. Chem. 2007, 50, 2708-2717.

16. Schneider, G.; N eidhart, W. ; G iller, T.; Sch mid, G. "S caffold-Hopping" b y Topological Pharmacophore Search: A Contribution to Virtual Screening. Angew. Chem. Int. Ed. Engl. 1999, 38, 2894-2896.

17. Abolmaali, S.F.; Ostermann, C.; Zell, A. The Compressed Feature Matrix--a novel descriptor for adaptive similarity search. J. Mol. Model. 2003, 9, 66-75.

18. Renner, S .; Schneide r, G. S caffold-hopping potential o fl igand-based si milarity concept s. ChemMedChem 2006, 1, 181-185.

19. Barker, E.J.; Buttar, D.; Cosgrove, D.A.; Gardiner, E.J.; Kitts, P.; Willett, P.; Gillet, V.J. Scaffold hopping using clique detection applied to reduced graphs. J. Chem. Inf. Model. 2006, 46, 503-511.

20. Naerum, L.; Norskov-La uritsen, L.; Olesen, P.H. Scaffold hopping and optim ization towards libraries of glycogen synthase kinase-3 inhibitors. Bioorg. Med. Chem. Lett. 2002, 12, 1525-1528.

21. Lloyd, D.G.; Buenemann, C.L.; Todorov, N.P.; Manallack, D.T.; Dean, P.M. Scaffold hopping in de novo design. Ligand generation in the absence of receptor information. J. Med. Chem. 2004, 47, 493-496.

22. Nair, P .C.; Sobhia, M.E. Fingerprint Direct ed Scaffold Hopping fo r Identificati on of CCR2 Antagonists. J. Chem. Inf. Model. 2008, 48, 1891-1902.

23. Mason, J.S.; Morize, I.; Menard, P.R.; Cheney, D.L.; Hulme, C.; Labaudiniere, R.F. New 4-point pharmacophore $\mathrm{m}$ ethod for $\mathrm{m}$ olecular similarity and di versity applications: ov erview of the method and appli cations, including a novel ap proach to the de sign of co mbinatorial libraries containing privileged substructures. J. Med. Chem. 1999, 42, 3251-64.

24. Andrews, K.M.; Cramer, R.D. Toward general methods of targeted library design: topomer shape similarity searching with diverse structures as queries. J. Med. Chem. 2000, 43, 1723-1740.

25. Jenkins, J.L.; Glick, M.; D avies, J.W. A 3D similarity method for sca ffold hopping from known drugs or natural ligands to new chemotypes. J. Med. Chem. 2004, 47, 6144-6159.

26. Bohl, M.; Dunbar, J.; Gifford, E. M.; Heritage, T.; Wild, D .J.; Willett, P.; Wilton, D.J. Scaffold Searching: Automated Identification of Similar Ring Sy stems for the Design of Combinatorial Libraries. Quant. Struct.-Act. Relat. 2002, 21, 590-597.

27. Jorgensen, W.L. Rusting of the lock and key model for protein-ligand binding. Science 1991, 254, 954-955.

28. Grant, M.A. Protein structure pred iction in struct ure-based ligand design and virt ual screening. Comb. Chem. High Throughput Screening 2009, 12, 940-960. 
29. Aronov, A.M.; Baker, C.; Bemis, G.W.; Cao, J.; Chen, G.; Ford, P.J.; Germann, U.A.; Green, J.; Hale, M.R.; Jacobs, M.; Janetka, J.W.; Maltais, F.; Martinez-Botella, G.; Namchuk, M.N.; Straub, J.; Tang, Q .; X ie, X. Flipped out: structure-guided design of selectiv e p yrazolylpyrrole ERK inhibitors. J. Med. Chem. 2007, 50, 1280-1287.

30. Trejo, A .; Arzeno, H.; Browner, M.; Ch anda, S.; Che ng, S.; Comer, D. D.; Dalrymple, S .A.; Dunten, P.; Lafargu e, J.; Lovejoy, B.; Freire-Moar, J.; Lim, J.; McIntosh, J.; Miller, J.; Papp, E.; Reuter, D.; Roberts, R.; Sanpablo, F.; Saunders, J.; Song, K.; Villasenor, A.; Warren, S.D.; Welch, M.; Weller, P.; Whiteley, P.E.; Zeng, L.; Goldstein, D.M. Design and synthesis of 4-azaindoles as inhibitors of p38 MAP kinase. J. Med. Chem. 2003, 46, 4702-13.

31. Berman, H.M.; Westbrook, J.; Feng, Z.; Gilliland, G.; Bhat, T.N.; Weissig, H.; Shindyalov, I.N.; Bourne, P.E. The Protein Data Bank. Nucleic Acids Res. 2000, 28, 235-42.

32. Scapin, G.; Pate 1, S.B.; Lisnock, J .; B ecker, J.W.; LoGrasso, P.V . The structure of JNK3 in complex with small molecule inhibitors: structural basis for p otency and selectivity. Chem. Biol. 2003, 10, 705-712.

33. Ogata, K.; Isomura, T.; Yamashita, H.; Kubodera, H., A Quantitative Approach to the Estimation of Chemical Space from a Given Geometry by the Combination of Atomic Species. QSAR Comb. Sci. 2007, 26, 596-607.

34. Rishton, G.M. Nonleadlikeness and leadlikeness in b iochemical screening. Drug Discov. Today 2003, 8, 86-96.

35. Lipinski, C.A. Drug-like properties and the causes of poor solubility and poor per meability. $J$. Pharmacol. Toxicol. Methods 2000, 44, 235-249.

36. Wang, J.; Wolf, R.M.; Caldw ell, J.W.; Kollman, P.A.; Case, D.A. Development and testing of a general amber force field. J. Comput .Chem. 2004, 25, 1157-1174.

37. Ooi, T.; Oobatake, M.; Nemethy, G.; Scheraga, H.A. Accessible surface areas as a measure of the thermodynamic par ameters of hydration of pe ptides. Proc. Natl. Acad. Sci. USA 1987, 84, 3086-3090.

38. Peifer, C.; Kinkel, K.; Abadleh, M .; S chollmeyer, D.; Laufer, S . From five- to six-membered rings: 3,4-diarylquinolinone as lead for novel p38MAP kinase inhibitors. J. Med. Chem. 2007, 50, 1213-21.

39. Kulkarni, R.G.; Sr ivani, P ; Achaiah, G.; Sastry , G.N. Strate gies to design py razolyl ur ea derivatives for p38 ki nase inh ibition: a molecular modeling study. J. Comput. Ai ded Mol. Des. 2007, 21, 155-66.

40. Gaillard, P.; Jeanclaude-Etter, I.; A rdissone, V.; Arkinstall, S.; Cambet, Y.; Camps, M.; Chabert, C.; Church, D.; Cirillo, R.; Gretener, D.; Halazy, S.; Nichols, A.; Szyndralewiez, C.; Vitte, P.A.; Gotteland, J.P. Design and synthesis of the first generation of novel potent, selective, and in vivo active (ben zothiazol-2-yl)acetonitrile inhi bitors of the c-Jun N-ter minal kin ase. J. Med. Chem. 2005, 48, 4596-4607.

41. Xie, X.; Gu, Y.; Fox, T.; Coll, J.T.; Fleming, M.A.; Markland, W.; Caron, P.R.; Wilson, K.P.; Su, M.S. Cry stal st ructure of JNK 3: a kinase i mplicated in n euronal apoptosis. Structure 1998, 6, 983-991. 
42. Lombardino, J.G. Pre paration of Some 4-Hydroxyl-1-Methyl-1h-2.1-Benzothiazine-3Carboxanilide 2,2-Dioxides. J. Heterocycl. Chem. 1972, 9, 315-317.

43. Coppo, F .T.; Fawzi, M.M. Novel heterocycles. S ynthesis of 2,3-dihydro-6-methyl-2 -phenyl-4H,6H-pyrano[3,2-c][2,1]benzothiazin-4-one 5,5-dioxide a nd related compounds. $J$. Heterocycl. Chem. 1998, 35, 983-987.

44. Coppo, F. T.; Fawzi, M.M. Synthesis of 1-methyl-7-(trifluoromethyl)-1H-pyrido[2,3-c] [1,2]thiazin-4(3H)-one 2,2-dioxide. J.Heterocycl. Chem. 1998, 35, 499-501.

45. Coppola, G.M.; Hardtm ann, G.E. Novel Hete rocycles .4. Sy nthesis of the Pyrido[2,3-C]1,2-Thiazine Ring-System. J. Heterocycl.Chem. 1979, 16, 1361-1363.

Sample Availability: Samples of the compounds are available from the authors.

(C) 2010 by the authors; lic ensee MDPI, Basel, Switze rland. This article i s an Open Access articl e distributed under the ter $\mathrm{ms}$ and cond itions of the Creative Commons Attribu tion license (http://creativecommons.org/licenses/by/3.0/). 